\title{
A cost minimisation analysis of a telepaediatric otolaryngology
} service

\author{
Cathy Q Xu*1, Anthony C Smith ${ }^{1}$, Paul A Scuffham² and Richard Wootton ${ }^{1}$
}

Address: ${ }^{1}$ Centre for Online Health, University of Queensland, Level 3 Foundation Building, Royal Children's Hospital, Herston, Queensland 4029, Australia and ${ }^{2}$ School of Medicine, Griffith University, Logan Campus, Meadowbrook, Queensland 4131, Australia

Email: Cathy Q Xu* - c.xu@uq.edu.au; Anthony C Smith - a.smith@pobox.com; Paul A Scuffham - p.scuffham@griffith.edu.au; Richard Wootton - r_wootton@pobox.com

* Corresponding author

Published: 4 February 2008

BMC Health Services Research 2008, 8:30 doi:10.1186/1472-6963-8-30

This article is available from: http://www.biomedcentral.com/I472-6963/8/30

(c) 2008 Xu et al; licensee BioMed Central Ltd.

This is an Open Access article distributed under the terms of the Creative Commons Attribution License (http://creativecommons.org/licenses/by/2.0), which permits unrestricted use, distribution, and reproduction in any medium, provided the original work is properly cited.
Received: 7 June 2007

Accepted: 4 February 2008

\begin{abstract}
Background: Paediatric ENT services in regional areas can be provided through telemedicine (tele-ENT) using videoconferencing or with a conventional outpatient department ENT service (OPD-ENT) in which patients travel to see the specialist. The objective of this study was to identify the least-cost approach to providing ENT services for paediatric outpatients.
\end{abstract}

Methods: A cost-minimisation analysis was conducted comparing the annual costs of the two modes of service provided by the Royal Children's Hospital (RCH) in Brisbane. Activity records were reviewed to analyse volume of activity during a 12 month period in 2005 , i.e. number of clinics, duration of clinics, number of consultations via telemedicine and in outpatient clinics, diagnoses, and travel related information. A sensitivity analysis was conducted using factors where there was some uncertainty or potential future variation.

Results: During the study period, 88 ENT consultations were conducted via videoconference for 70 patients at Bundaberg Base Hospital. 177 ENT consultations were conducted at the $\mathrm{RCH}$ for 117 patients who had travelled from the Bundaberg region to Brisbane. The variable cost of providing the tele-ENT service was A\$I08 per consultation, compared with $A \$ 155$ per consultation for the conventional outpatient service. Telemedicine was cheaper when the workload exceeded 100 consultations per year. If all 265 consultations were conducted as teleENT consultations, the cost-savings would be $\$ 7,621$.

Conclusion: The cost-minimisation analysis demonstrated that under the circumstances described in this paper, the tele-ENT service was a more economical method for the health department of providing specialist ENT services.

\section{Background}

Delivering specialty care to children living in the vast region of Queensland is challenging and often requires patients to travel to tertiary centres for specialist consultations. In some circumstances, specialists travel to regional hospitals to conduct outreach clinics. The cost to families and the healthcare system is substantial. For example, the State Government's health department in Queensland (Queensland Health) provides financial assistance to patients who need access to specialist medical services, through the Patient Travel Subsidy Scheme. In the 2005- 
2006 financial year, $\$ 28$ million was spent on patient travel [1].

Ear, nose and throat (ENT) disorders are common and represent a large proportion of healthcare problems in children. Consequently, there is a high rate of referrals to ENT specialty clinics [2-5]. In North Queensland, the prevalence of childhood ENT problems, especially otitis media, is extremely high (66\%-95\%) among aboriginal children [6-8]. The Royal Children's Hospital (RCH) in Brisbane is one of two major paediatric tertiary referral hospitals which service Queensland. In 2005, there were 4,819 ENT outpatient department consultations (OPD) and 1,980 ENT inpatient admissions to the hospital.

Telemedicine has been used for the pre-screening of potential ENT surgical patients as part of a research project facilitated by the University of Queensland's Centre for Online Health (COH) [9]. Since 2003, patients in selected regional areas have been referred by their local primary healthcare providers to a telemedicine clinic at their local hospital. Instead of travelling to Brisbane to see the specialist, an ENT consultation is conducted via videoconference. During the videoconference appointment, an ENT examination is carried out using a video-otoscope connected to the videoconference system. The specialist is able to view real-time ENT images at a bandwidth of 384 $\mathrm{kbit} / \mathrm{s}$ as well as hearing test results and X-rays transmitted via a document camera. Connected at a distance by a videoconference system, the specialist can discuss the history and clinical findings with the patient/family and the local paediatrician in order to make a decision about diagnosis and clinical management (Figure 1). A coordinator based

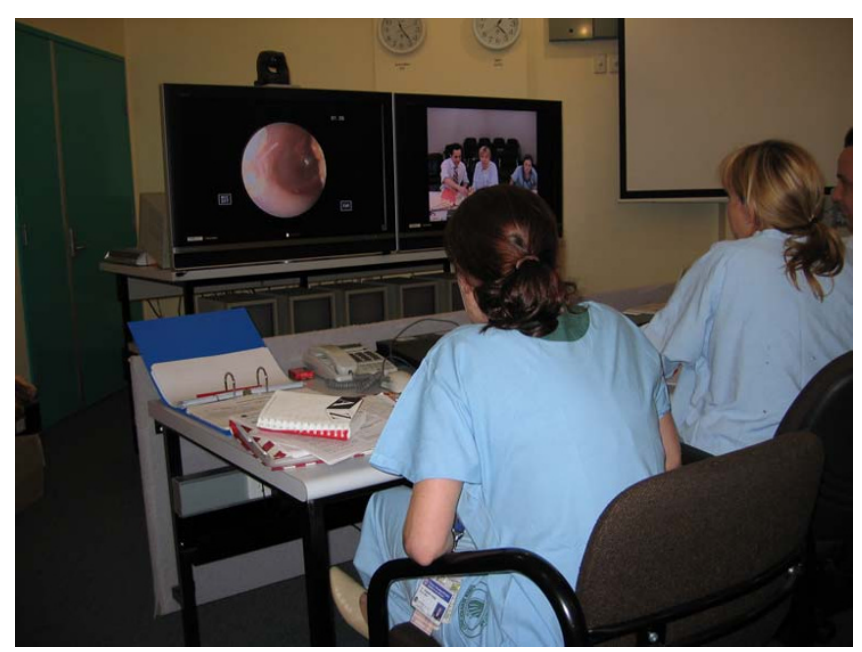

Figure I

Tele-ENT clinic in progress. The specialist is able to view video-otoscopic images during a videoconference appointment. at $\mathrm{COH}$ travels to the regional site and provides technical support during each clinic session.

Bundaberg is the region where the pilot tele-ENT work has been carried out. Bundaberg is a coastal region situated approximately $385 \mathrm{~km}$ north of the Brisbane (Figure 2). The population of Bundaberg and surrounding area is about 74,000 [10]. In 2005, the RCH conducted 177 conventional outpatient ENT (OPD-ENT) consultations for children referred from Bundaberg. In addition, a total of 88 ENT consultations were conducted by telemedicine.

There are very few studies which have compared the clinical outcomes and costs of telemedicine services to the costs of conventional outpatient services; there are almost none in the area of tele-ENT. Pedersen first reported the use of endoscopic cameras and videoconferencing systems in Norway $[11,12]$. Tele-ENT has also been described as a useful application in military medicine [13]. Previous work done in Queensland demonstrated the feasibility of videoconferencing for the assessment of otolaryngology conditions during the pre-screening of potential surgical patients. The study described potential savings from the use of telemedicine and suggested that further studies were required on the cost-effectiveness [9]. The objective of the present study was to identify the least-cost approach to providing ENT services for paediatric outpatients in a regional town in Queensland.

\section{Methods}

We conducted a cost-minimisation analysis to compare the cost of the tele-ENT service in Bundaberg to the cost of providing the conventional $\mathrm{RCH}$ outpatient service for patients travelling from Bundaberg. We analysed the annual cost of the tele-ENT service for the 2005 calendar year. This was compared with the cost of the conventional outpatient service during the same 12-month period. The outcomes of the consultations were assumed to be the same whether delivered face-to-face or by telemedicine.

Study subjects were:

A. Patients who attended tele-ENT clinics in Bundaberg for their appointments. These patients were referred by the paediatrician who participated in the tele-ENT clinics.

B. Patients who travelled to Brisbane and visited OPDENT clinics at RCH for their regular appointments. They were referred by other physicians in Bundaberg.

ENT service information was obtained from the RCH information system and the telepaediatric service activity records maintained by the $\mathrm{COH}$. Clinical information was collected from RCH medical records. Travel costs and reimbursement information was obtained from the Bun- 


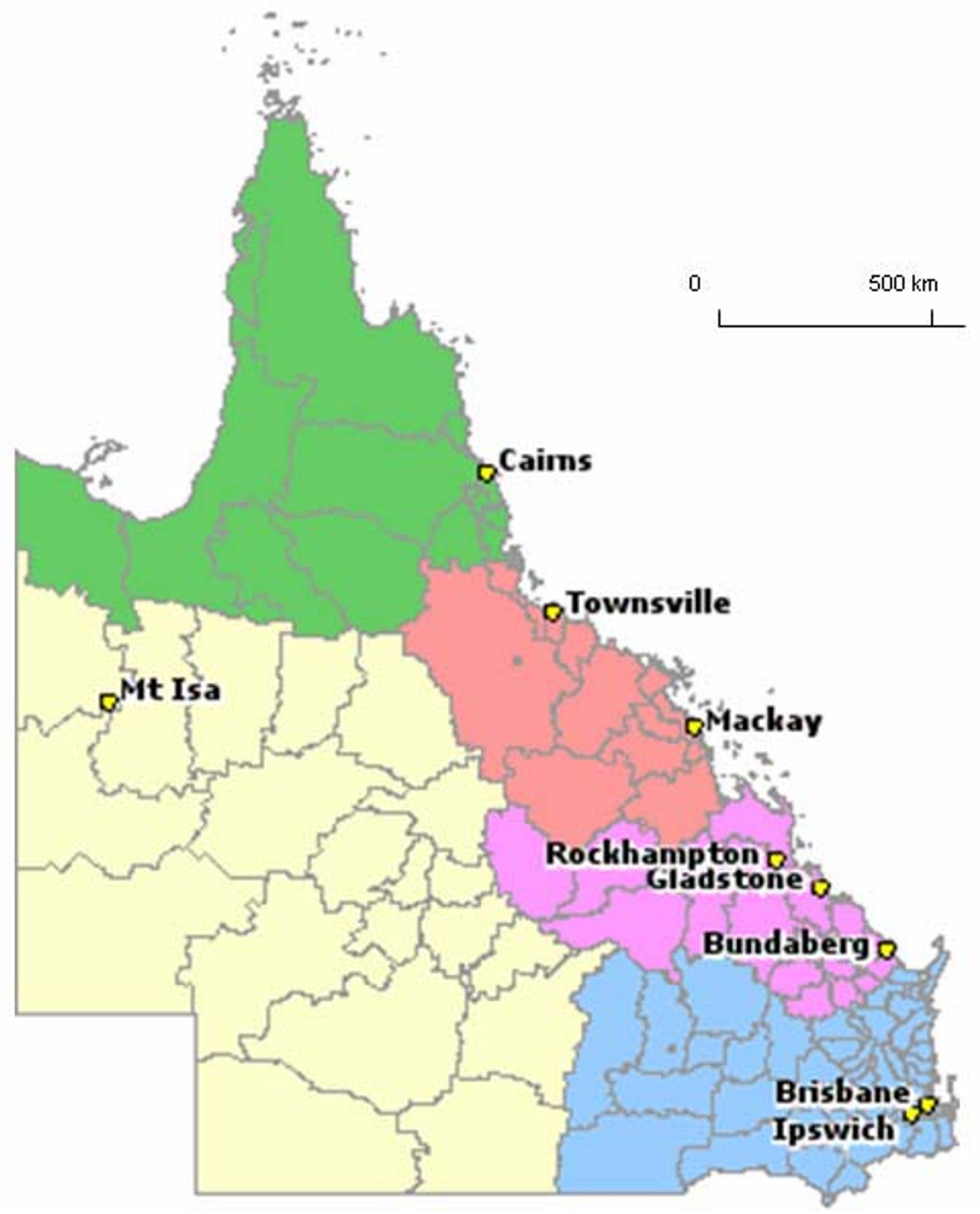

Figure 2

Map of Queensland. 
daberg Base Hospital Travel Office and from the Patient Travel Subsidy Scheme (PTSS).

The following data were collected: number of clinics, duration of the clinic, number of patients and consultations via telemedicine, number of patients visiting $\mathrm{RCH}$ and outpatient consultations provided, diagnoses, travel distance and travel mode (e.g. by car, rail or air), and travel reimbursement information.

\section{Cost Minimisation Analysis}

We calculated the fixed and variable costs of providing the ENT services using a costing model similar to other reported studies [14-19]. Tele-ENT service costs were classified as either fixed or variable costs. Fixed costs are those that are independent of the number of patients using the service, such as equipment and facilities. Variable costs are the associated costs of conducting each consultation. All costs were described in 2005 Australian dollars $(\mathrm{A} \$ 1 \approx$ US\$0.80).

Fixed costs were a video-otoscope (Flexiscope Microvision ENT Camera, Inline Systems) and a document camera used to transmit images of hard copy documents such as hearing tests and X-rays. Annual equivalent costs were calculated over a period of five years using an annual discount rate of $5 \%$. Since both the RCH and the regional centre had existing videoconferencing equipment and ISDN lines (for other telehealth services and education programmes), the proportion of the fixed costs of these items ascribed to ENT would have been very small and therefore they were ignored. Facility costs were also excluded as both services utilized existing hospital infrastructure.

Variable costs were based on the standard charges and rates in Queensland. These included staff salaries and travel costs, ISDN line charges and patient travel costs. The time and duration of a consultation depends on the subspecialty and nature of the consultation. The average teleENT consultation time per patient was about 10 minutes, i.e. it was similar to an outpatient face-to-face ENT consultation time. Therefore, the cost of the ENT specialist's time was about the same, regardless of mode of consultation, and was excluded.

Table I: Tele-ENT and OPD-ENT activity involving patients from Bundaberg (2005)

\begin{tabular}{lrr}
\hline & Tele-ENT & OPD-ENT \\
\hline Number of patients & 70 & 117 \\
Number of consultations & 88 & 177 \\
Number of consultations per patient & 1.3 & 1.5 \\
\hline
\end{tabular}

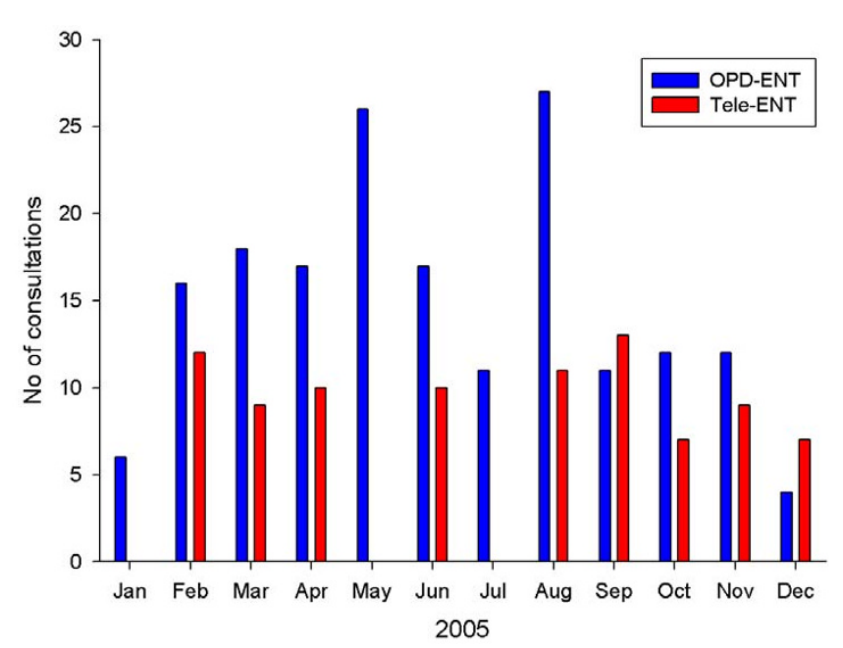

Figure 3

ENT clinical activity in 2005 (both modalities).

Patients who were referred to the RCH for outpatient consultations were eligible for reimbursement for part of their travel cost through the PTSS. The Bundaberg Hospital travel office reported that most patients who visited RCH travelled by rail in 2005. The cost calculation for travel was therefore based on the rail fare. For an outpatient visit, the patient/family was funded for a return trip and accommodation for one night. However, only some families lodged claims or made travel arrangements through the hospital travel office in Bundaberg. Therefore, we calculated the annual costs to the health department based on the number of consultations conducted during 2005, rather than PTSS bookings or claims through the travel office. Additional costs to the family, such as time off work, parking, fuel and meals were not analysed during this study.

Because this study was designed as a cost-minimisation analysis, the threshold (break-even point) at which the tele-ENT service became less costly than the OPD-ENT service was estimated. A sensitivity analysis was conducted using factors where there was some uncertainty or potential future variation. These factors were related to the cost and usage of the video-otoscope, ISDN line charges and the proportion of patients who utilised the PTSS. The tele-ENT project was approved by the appropriate ethics and hospital committees. Ethics permission was not required for the cost analysis.

\section{Results}

In 2005, nine tele-ENT clinic sessions were conducted and a total of 88 ENT consultations were provided via videoconference for 70 patients at Bundaberg Base Hospital. The average number of consultations was 7 per month over the 12-month period, ranging from 7 to 13 consulta- 
Table 2: Clinical findings (diagnosis) reported during the specialist examination*

\begin{tabular}{lcccc}
\hline & Tele-ENT & & OPD-ENT \\
\hline Diagnoses & Number of conditions & Proportion (\%) & Number of conditions & Proportion (\%) \\
\hline Otitis media & 32 & 31 & 99 & 43 \\
Recurrent tonsillitis & 23 & 23 & 34 & 15 \\
Obstructive sleep apnoea & 12 & 12 & 27 & 12 \\
Rhinitis & 10 & 10 & 61 & 2 \\
Other & 24 & 1 & 4 & 27 \\
Normal & 1 & 100 & 230 & 100 \\
\hline Total & 102 & & 24 & 2 \\
\hline
\end{tabular}

* Note: some patients had multiple conditions

tions each month (excluding case discussion sessions when patients were not present). The average number of consultations via telemedicine was 1.3 per patient over the 12-month study period (Table 1).

The conventional OPD-ENT service provided 177 face-toface consultations for 117 patients who had travelled from Bundaberg. The average number of consultations in this group was 15 per month, ranging from 4 to 27 consultations each month. The average number of consultations per patient was 1.5 in 2005 (see Table 1, Figure 3).

\section{Clinical categories}

Medical chart reviews confirmed that the types of cases diagnosed during the tele-ENT and OPD-ENT clinics were similar (Table 2). The main diagnoses were otitis media, recurrent tonsillitis, obstructive sleep apnoea, grommets review, hearing loss, allergic rhinitis and cleft palate reviews. We found that there were substantial differences in the proportion of certain conditions diagnosed in each group, which we suspect was mainly because subjects were sorted according to mode of consultations rather than actual clinical conditions.

\section{Tele-ENT service costs}

The service was provided in pre-existing paediatric telehealth facilities at both the RCH and the Bundaberg Base Hospital. The initial cost of the video-otoscope was $\$ 15,000$ and the cost of a document camera was $\$ 5,000$. Assuming these pieces of equipment both have a life of five years, and using a discount rate of $5 \%$, the annual equivalent cost of the equipment was $\$ 4,620$ (Table 3 ).

Variable costs included a local paediatrician's salary at an average rate of $\$ 150$ per hour for a duration of 2 hours per clinic. Other variable costs included a technician's salary of $\$ 30$ per hour for one working day ( 8 hours), the technician's return airfare and ISDN line charges at a rate of

Table 3: Summary of costs for the tele-ENT and OPD-ENT service

\section{Tele-ENT (\$) OPD-ENT (\$)}

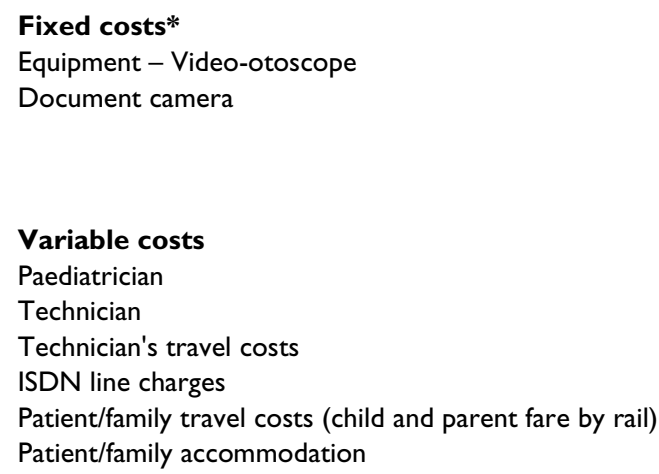

*Annual equivalent cost depreciated over 5 years at $5 \%$
Sub total

$\begin{array}{ccc} & 2700 & 0 \\ & 2160 & 0 \\ & 2700 & 0 \\ & 1980 & 0 \\ & 0 & 16,744 \\ \text { Sub total } & 0 & 10,620 \\ & 9540 & 27,364 \\ \text { Total cost } & \mathbf{1 4 , 1 6 0} & \\ & \mathbf{1 0 8} & \mathbf{2 7 , 3 6 4} \\ & \mathbf{1 5 5}\end{array}$


Table 4: Variable costs for the tele-ENT service

\begin{tabular}{|c|c|c|c|c|}
\hline Variable costs & Rate & Clinic duration & Number of clinics & Annual costs (\$) \\
\hline Paediatrician's salary & $\$ 150 /$ hour & 2 hours & 9 & 2700 \\
\hline Air travel & $\$ 300 /$ trip & I return trip & 9 & 2700 \\
\hline Technician $(\$ 30 \times 8 \mathrm{hr})$ & $\$ 240 /$ day & 8 hours & 9 & 2160 \\
\hline ISDN line charges & $\$ 110 /$ hour & 2 hours & 9 & 1980 \\
\hline Total variable cost & & & & 9540 \\
\hline
\end{tabular}

$\$ 110$ per hour. Table 4 lists the total variable costs of the tele-ENT service.

The average variable cost per consultation was $\$ 108$ using the tele-ENT service. The annual cost of providing 88 consultations was $\$ 14,160$. The estimated total annual costs would have been $\$ 33,348$ if all ENT consultations (265) had been conducted via telemedicine at a variable cost of $\$ 108$ each plus fixed costs of $\$ 4,620$.

\section{OPD-ENT service costs}

The Queensland Health PTSS reimbursement for Bundaberg patients was $\$ 94.60$ ( $\$ 30.80$ for a child plus $\$ 63.80$ for the escort) for travel by rail to Brisbane. Accommodation assistance was provided to the patient and an approved escort of up to $\$ 30$ per person per night. Thus, for a paediatric OPD appointment, the accommodation cost was $\$ 60$. For the 177 OPD consultations conducted in 2005, the estimated costs of travel by train and accommodation were $\$ 16,744$ and $\$ 10,620$ respectively. Thus, the average estimated travel cost per OPD consultation was $\$ 155$. Assuming all ENT consultations conducted in 2005 were conducted in outpatients (OPD-ENT), the estimated annual travel costs would have been $\$ 41,075$ (i.e. 265 consultations at $\$ 155$ each).

\section{Threshold}

During the study, the total cost for an OPD consultation was $\$ 155$ per consultation and for tele-ENT the cost was $\$ 161$ per consultation. The variable costs were less for

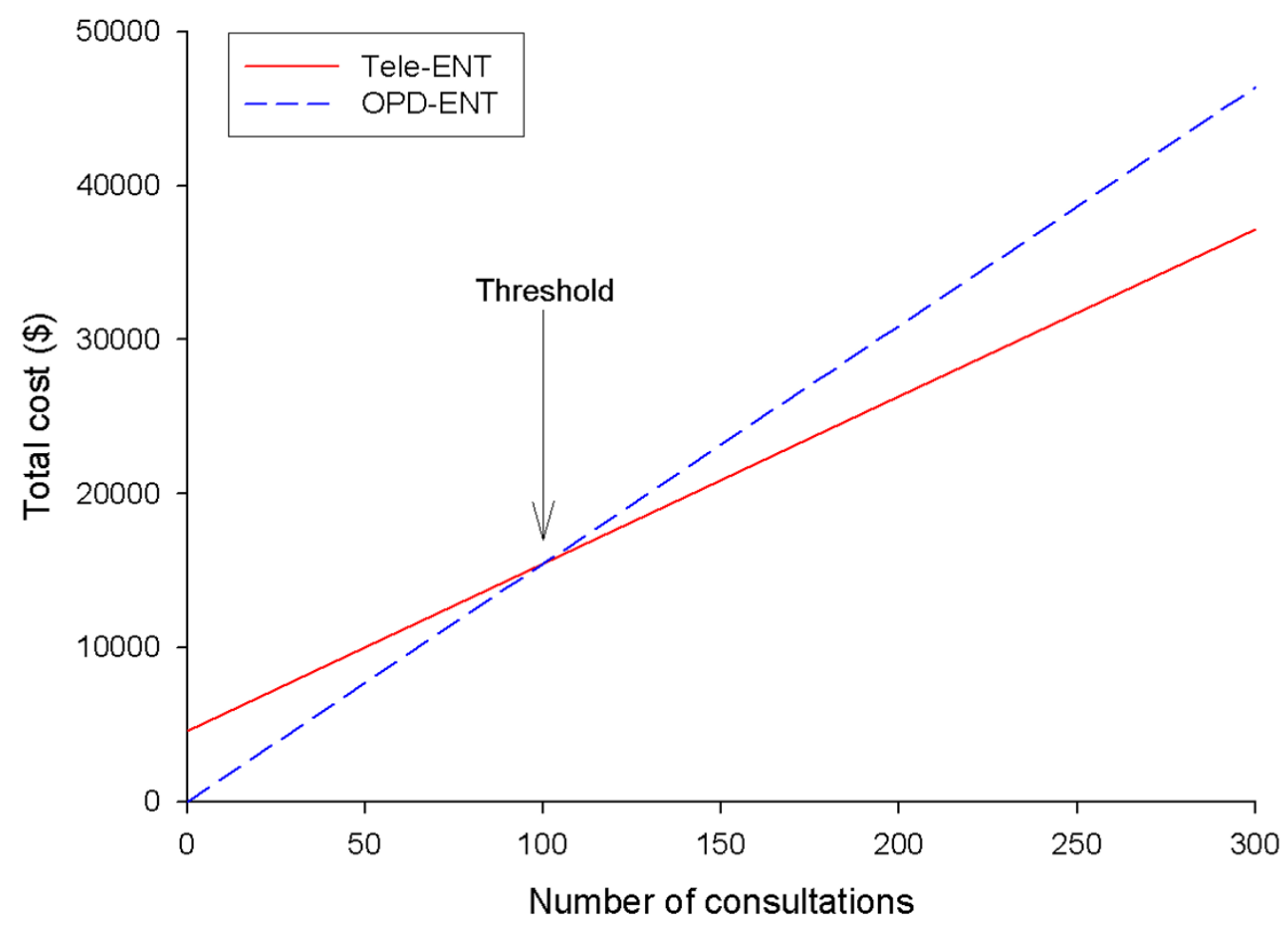

Figure 4

Threshold analysis. 
Table 6: Estimated costs of videoconference equipment and telecommunications for a new site

\begin{tabular}{|c|c|c|c|c|}
\hline Fixed costs & Provider site (\$) & Patient site (\$) & Total (\$) & Annual equivalent cost (\$) \\
\hline Videoconference unit & 7000 & 7000 & 14,000 & 3234 \\
\hline TV monitor & 500 & 500 & 1000 & 230 \\
\hline ISDN installation ${ }^{2}$ & 885 & 885 & 1770 & $\mathrm{n} / \mathrm{a}$ \\
\hline Video-otoscope & 0 & 15,000 & 15,000 & 3465 \\
\hline Document camera & 0 & 5000 & 5000 & 1155 \\
\hline Trolley & 750 & 750 & 1500 & 346 \\
\hline ISDN line renta| ${ }^{3}$ & 2160 & 2160 & 4320 & 4320 \\
\hline Total & II,295 & 20,295 & 31,590 & 12,750 \\
\hline
\end{tabular}

I Depreciated at $5 \%$ annually with no resale value at the end of 5 years.

2 This is a sunk cost occurring in year one only.

33 ISDN lines for 12 month ( $\$ 60$ per line per month).

tele-ENT compared with OPD ( $\$ 108$ vs $\$ 155$ ). Thus, teleENT was slightly more costly than OPD due to the fixed costs for the video-otoscope and document camera. We calculated the threshold (break-even point) at which the tele-ENT service became less costly than the OPD-ENT service (Figure 4). The threshold point was 100 consultations. That is, additional tele-ENT consultations above this threshold were cost-saving for the health department compared with outpatient consultations. The difference between conducting all 265 consultations conventionally and all 265 by telemedicine was a cost-saving of $\$ 7,621$.

\section{Sensitivity analysis}

The sensitivity analysis showed that the expected useful life of the video-otoscope was a key factor; the effect on the results of changes in the life of the instrument was greater than the effect of changes in the initial cost of the instrument. The costs of accommodation and travel were also important factors; when these costs were increased, fewer OPD-ENT consultations were required for tele-ENT to become cost-saving. Similarly, when the costs of ISDN line charges were reduced by $50 \%$, fewer consultations were required for tele-ENT to be cost-saving. The travel costs for a technician had a relatively substantial effect on the result. For example, when these were increased by $50 \%, 147$ consultations would need to be performed by tele-ENT for the service to be cost-saving. However, if a local technician could be employed or seconded on a prorata basis, travel costs would reduce towards zero. Under this scenario, tele-ENT becomes cost-saving when 60 consultations are undertaken. The discount rate had a relatively small effect only (Table 5).

The above calculations were based on both specialist and regional centres having existing videoconferencing equipment and ISDN telecommunications. If a tele-ENT service was to be introduced to a location that did not have this infrastructure, additional expenditure would be required.
To establish a new site, the fixed costs would increase to include basic videoconferencing equipment and installation of telecommunications. We estimate these would cost an annual equivalent of $\$ 12,750$ over a five-year period (see Table 6).

\section{Discussion}

There is an emerging literature on the utility and efficacy of telemedicine. However, studies of the cost effectiveness of telemedicine practice have been limited. According to a number of systematic reviews, there is a lack of persuasive evidence about whether telemedicine is a cost-effective way of delivering health care $[20,21]$. The present study suggests that from the perspective of the health service provider, the tele-ENT service is less expensive than the conventional OPD service in existing telehealth facilities as shown in Table 3. The tele-ENT service was cheaper when the workload exceeded 100 consultations per year. This is significant to the region of Bundaberg where 265 ENT consultations took place in 2005. Our finding is consistent with other studies that suggest that with a higher number of telemedicine consultations, greater savings are made by the health service provider $[14,17,19]$.

In the case of Bundaberg, 33\% of all ENT consultations were conducted via telemedicine in 2005. If each telemedicine consultation was a direct substitute for an outpatient consultation, then the tele-ENT service was cost-saving. This suggests that potential savings to the health system could be obtained if telemedicine was utilized on a wider scale for paediatric ENT services, particularly for regions with similar patient referral rates and at similar or greater distances from the specialist centre.

In principle, the service could be expanded to other suitable sites without a major increase in fixed costs, especially in locations with existing telemedicine facilities. However, there are a number of factors that need to be considered 
Table 5: Sensitivity analysis

\begin{tabular}{|c|c|}
\hline Adjusted unit costs & Workload (number of consultations) required for threshold to be reached \\
\hline Base case & 100 \\
\hline \multicolumn{2}{|l|}{ Video-otoscope } \\
\hline cost $=\$ 12,000$ & 85 \\
\hline cost $=\$ 18,000$ & 115 \\
\hline life $=3$ years & 144 \\
\hline life $=8$ years & 75 \\
\hline discount rate $=3 \%$ & 96 \\
\hline discount rate $=10 \%$ & 111 \\
\hline \multicolumn{2}{|l|}{ Document camera } \\
\hline $\cos t=\$ 4000$ & 95 \\
\hline cost $=\$ 6000$ & 105 \\
\hline life $=3$ years & 115 \\
\hline life $=8$ years & 95 \\
\hline discount rate $=3 \%$ & 99 \\
\hline discount rate $=10 \%$ & 104 \\
\hline \multicolumn{2}{|c|}{ Proportion seeking reimbursement for travel } \\
\hline $90 \%$ & 150 \\
\hline $80 \%$ & 303 \\
\hline \multicolumn{2}{|l|}{ Travel cost } \\
\hline$\$ 115$ & 69 \\
\hline$\$ 125$ & 60 \\
\hline \multicolumn{2}{|c|}{ Accommodation allowance } \\
\hline$\$ 40$ & 70 \\
\hline$\$ 50$ & 54 \\
\hline \multicolumn{2}{|l|}{ ISDN line charges } \\
\hline$\$ 1000$ & 81 \\
\hline$\$ 3000$ & 134 \\
\hline \multicolumn{2}{|l|}{ Technician's travel costs } \\
\hline$\$ 0$ & 60 \\
\hline$\$ 1350$ & 75 \\
\hline$\$ 4000$ & 147 \\
\hline
\end{tabular}

should tele-ENT services be expanded. These include the availability of ENT specialists, involvement of regional clinical staff and technical support. The service also relies on an adequate telemedicine infrastructure.

Although not formally measured in the present analysis, the family costs of not having to travel to Brisbane to see a specialist should be acknowledged. This is certainly the case for families living in the rural areas where specialist services are lacking. Smith et al (2003) compared the family costs of attending hospital outpatient appointments via videoconference and in person. The results of that economic study suggested that it was much more expensive and inconvenient to travel to the RCH for an outpatient consultation than it was to attend a telepaediatric consultation at a regional hospital [22].

Travel to Brisbane from Bundaberg usually takes 5-6 hours by car or train - one way. From the health department's perspective, tele-ENT cost an additional A $\$ 6$ per consultation more than OPD during the study period; however, each additional tele-ENT consultation would save the health department $\$ 46$ because all fixed costs have been covered. In addition, many regional families have no choice but to take time off work to attend an appointment in Brisbane and children are unable to attend school. There are also out-of-pocket expenses which are not reimbursed by the health service such as child care costs, meals and parking fees. If all of these costs were taken into consideration, the overall societal economics of doing telemedicine would have been even more favourable.

Few studies have examined the clinical outcomes of teleENT in comparison to OPD-ENT consultations. Several studies have investigated the accuracy of pre-recorded digital images and found over $80 \%$ concordance compared with follow-up and real-time consultations $[23,24]$. There are a number of studies which have compared real-time and store-and forward ENT tele-consultations. These studies found a higher rate of diagnostic accuracy using realtime methods $[25,26]$. A recent study examined the accuracy of real-time telemedicine for paediatric ENT preadmission screening. Data on the patient's initial video- 
conference diagnosis and management strategy were compared to eventual primary diagnosis and patient care. The diagnostic and treatment agreement were both over $90 \%$ [27].

There are certain limitations in the present study. We assumed that the clinical outcome from a tele-ENT consultation was similar to that from an outpatient consultation. Also there were substantial clinical variations between the two study groups since the clinical case-mix was not controlled. Finally, it was an observational study and not a randomised controlled trial. Thus the economics of using telemedicine for paediatric ENT assessments will require further investigation before definitive conclusions can be drawn.

\section{Conclusion}

In summary, the present study compared the costs of a tele-ENT service to the costs of providing OPD-ENT services in the conventional manner. The cost analysis was based on the annual activities during 2005, and suggests that savings to the health care system could be made when actual workload exceeded 100 tele-ENT consultations. The variable cost of tele-ENT consultation was less than the cost of travel to Brisbane from a regional area to attend OPD-ENT clinics.

\section{Competing interests}

The author(s) declare that they have no competing interests.

\section{Authors' contributions}

CX and RW conceived the study and conducted the analysis. CX produced the first draft of the manuscript. AS contributed to the analysis, study design, methodology and revisions of the manuscript. PS provided valuable guidance and contributed to the health economic evaluation. All authors contributed to the reviewing and editing of the manuscript. All authors read and approved the final manuscript.

\section{Acknowledgements}

Funding was provided by the Commonwealth Department of Health and Ageing (Medical Specialist Outreach and Assistance Programme), Royal Children's Hospital Foundation and Queensland Health. We thank the staff in the Bundaberg Base Hospital for their assistance with the clinics and for providing patient travel information.

\section{References}

I. Queensland Health: Queensland Health Annual Report 20052006. Brisbane Queensland Government 2006.

2. Hannaford PC, Simpson JA, Bisset AF, Davis A, McKerrow W, Mills $R$ : The prevalence of ear, nose and throat problems in the community: results from a national cross-sectional postal survey in Scotland. Family Practice 2005, 22(3):227-33.

3. Rob MI, Westbrook JI, Taylor R, Rushworth RL: Increased rates of ENT surgery among young children: Have clinical guidelines made a difference? Journal of Paediatrics and Child Health 2004, 40:624-632.
4. Harris C: Childhood ENT disorders: When to refer to specialists. Australian Family Physician 2002, 3 I (8):70I-4-7I6.

5. Donnelly MJ, Quraishi MS, McShane DP: ENT and general practice: A study of paediatric ENT problems seen in general practice and recommendations for general practitioner training in ENT in Ireland. Irish Journal of Medical Science 1995, 164(3):209-II.

6. ENT outreach project: Evaluation report. Australian Centre for Health Promotion; Sydney; 200I.

7. Morris P: A systematic review of clinical research addressing the prevalence, aetiology, diagnosis, prognosis and therapy of otitis media in Australian Aboriginal children. Journal of Paediatrics and Child Health 1998, 34(6):487-497.

8. Gruen RL, Bailie RS, d'Abbs PH, O'Rourke IC, O'Brien MM, Verma N: Improving access to specialist care for remote Aboriginal communities: evaluation of a specialist outreach service. Medical Journal of Australia 200 I, I 74:507-II.

9. Smith AC, Williams J, Agnew J, Sinclair S, Youngberry K, Wootton R: Real-time telemedicine for paediatric ENT pre-admission screening. Journal of Telemedicine and Telecare 2005, I I (Supplement 2):86-9.

10. Wikipedia: The Free Encyclopaedia. Queensland 2005 [http:// en.wikipedia.org/wiki/Bundaberg]. (last checked 5 March 2007)

II. Pedersen S, Hartviksen G, Haga D: Teleconsultation of patients with otorhinolaryngologic conditions. A tele-endoscopic pilot study. Archives of Otolaryngology-Head and Neck Surgery 1994, 120:133-6.

12. Pedersen S, Holand U: Tele-endoscopic otorhinolaryngological examination: preliminary study of patient satisfaction. Telemedicine Journal 1995, I:47-52.

13. Melcer T, Hunsaker D, Crann B, Caola L, Deniston W: A prospective evaluation of ENT telemedicine in remote military populations seeking specialty care. Telemedicine Journal and e-Health 2002, 8(3):30I-II.

14. Smith AC, Scuffham $P$, Wootton R: The costs and potential savings of a novel telepaediatric service in Queensland. $B M C$ Health Services Research 2007, 7:35.

15. Wootton R, Bloomer SE, Corbett R, Eedy DJ, Hicks N, Lotery HE, Mathews C, Paisley J, Steele K, Loane MA: Multicentre randomised control trial comparing real time teledermatology with conventional outpatient dermatological care: social cost-benefit analysis. British Medical Journal 2000, 320:1252-6.

16. Drummond MF, O'Brien B, Stoddart GL, Torrance GW: Methods for the Economic Evaluation of Health Care Programmes 2nd edition. Oxford University Press, Oxford; 1997.

17. Bergmo TS: An economic analysis of teleconsultation in otorhinolaryngology. Journal of Telemedicine and Telecare 1997, 3(4): 194-9.

18. Smith AC: The feasibility and cost-effectiveness of a novel telepaediatric service in Queensland. In PhD Thesis The University of Queensland, Australia; 2004.

19. Persaud D, Jreige S, Skedgel C, Finley J, Sargeant J, Hanlon N: An incremental cost analysis of telehealth in Nova Scotia from a social perspective. Journal of Telemedicine and Telecare 2005, I I:77-84.

20. Mair FS, Haycox A, May C, Williams T: A review of telemedicine cost-effectiveness studies. Journal of Telemedicine and Telecare 2000, 6(Supplement I):38-40.

21. Whitten PS, Mair FS, Haycox A, May C, Williams T, Hellmich S: Systematic review of cost effectiveness studies of telemedicine interventions. British Medical Journal 2002, 324(753 I): |434-7.

22. Smith AC, Youngberry K, Christie F, Isles A, McCrossin R, Williams $M, V a n$ der Westhuyzen J, Wootton R: The family costs of attending hospital outpatient appointments via videoconference and in person. Journal of Telemedicine and Telecare 2003, 9(Suppl 2: S2):58-61.

23. Patricoski C, Kokesh J, Ferguson AS, Koller K, Zwack G, Provost E, Holck P: A comparison of in-person examination and video otoscope imaging for typanostomy tube follow-up. Telemedicine Journal and e-Health 2003, 9(4):33I-44.

24. Smith AC, Perry C, Agnew J, Wootton R: Accuracy of prerecorded video images for the assessment of rural indigenous children with ear, nose and throat conditions. Journal of Telemedicine and Telecare 2006, I2(Supplement 3):76-80.

25. Sclafani AP, Heneghan C, Ginsburg J, Sabini P, Stern J, Dolitsky JN: Teleconsultation in otolaryngology: Live versus store and 
forward consultations. Otolaryngology-Head and Neck Surgery 1999, I 20(I):62-72.

26. Ullah R, Gilliland D, Adams D: Otolaryngology consultations by real-time telemedicine. Ulster Medical Journal 2002, 7 I (I):26-6.

27. Smith AC, Dowthwaite S, Agnew J, Wootton R: Accuracy of realtime telemedicine for paediatric otolaryngology pre-admission screening. Medical Journal of Australia 2008 in press.

\section{Pre-publication history}

The pre-publication history for this paper can be accessed here:

http://www.biomedcentral.com/1472-6963/8/30/prepub

Publish with Bio Med Central and every scientist can read your work free of charge

"BioMed Central will be the most significant development for disseminating the results of biomedical research in our lifetime. " Sir Paul Nurse, Cancer Research UK

Your research papers will be:

- available free of charge to the entire biomedical community

- peer reviewed and published immediately upon acceptance

- cited in PubMed and archived on PubMed Central

- yours - you keep the copyright

Submit your manuscript here:

http://www.biomedcentral.com/info/publishing_adv.asp 